\title{
Guest editorial: A call for health advocacy to be included as an outcome competency into optometric education programmes
}

Author:
Diane van Staden ${ }^{1}$
Affiliation:
'Department of Optometry,
Faculty of Health Sciences,
University of KwaZulu-Natal,
Durban, South Africa
Corresponding author:
Diane van Staden,
wallaced@ukzn.ac.za
How to cite this article:
Van Staden D. Guest
editorial: A call for health
advocacy to be included as
an outcome competency into
optometric education
programmes. Afr Vision Eye
Health. 2021;80(1), a708.
https://doi.org/10.4102/
aveh.v80i1.708
code with your
Reart phone or
mobile device
to read online.
Q 2021. The Author(s).
Licensee: AOSIS. This work
is licensed under the
Creative Commons
Attribution License.

The United Nations (UN) General Assembly recently adopted the first ever Resolution on Vision titled 'Vision for Everyone'. This ground-breaking resolution commits the international community to addressing the eye health needs of an estimated 1.1 billion people, who are living with preventable vision loss globally, by $2030 .{ }^{1}$ The agreement is significant as it is designed to tackle preventable vision loss by enshrining eye health as part of the United Nations' Sustainable Development Goals (SDGs). This means that, in order to achieve this goal, member states must ensure full access to eye care services for their populations, and make eye care part of their country's journey towards achieving the SDGs. The profession of Optometry is well positioned to address this need ${ }^{2}$; and indeed, should be at the forefront of efforts to do so since refractive error, which is easily correctable by a pair of spectacles, is the leading cause of moderate to severe visual impairment globally. ${ }^{3}$

In 2010, Frank et al. ${ }^{4}$ called for the transformation of health professions education programmes to strengthen health systems in our interdependent world. Following this landmark paper, numerous health professions training programmes across the world have introspected and either redesigned or restructured their curricula accordingly, mainly by adopting the CanMEDs framework which identifies and describes the abilities that health professionals require to effectively meet the healthcare needs of the people they serve. ${ }^{5}$ These include competencies in communication, collaboration, leadership, health advocacy, scholarship and professionalism.

Optometry training globally has generally not kept pace with developments in health professions education, specifically with regard to the inclusion of these expanded competencies into training programmes. This may be because optometrists have traditionally not been considered as part of the global health workforce, with the historical focus of public health services more on doctors, nurses and other allied health workers, and optometry instead seen mostly as a privatised health service, rather than an essential health service. ${ }^{6}$ However, inequities in the access to vision care that exist within and between countries, as well as global imperatives such as the UN Resolution on Vision, call for the profession of optometry, and optometry training programmes in particular, to be responsive to these changing needs. Central to this is the need for the inclusion of more holistic competencies such as those espoused in the CanMEDS framework, which address patient and population eye health needs, into training programmes; so that each trained professional embraces the role that they can play in advancing the global eye health agenda in support of the 'Vision for Everyone' imperative.

Health advocacy is one of these important competencies required in the training of optometrists, as it includes activities relating to ensuring access to care, navigating the health system, mobilising resources, addressing health inequities, influencing health policy and creating system change. ${ }^{7}$ All of these are relevant and necessary in the fight against avoidable vision impairment and the need to reduce eye health inequities by ensuring that eye health is fully integrated into health policy and practice. Therefore, there is a need to move beyond just providing training to develop clinical or technical skills in optometry, but also embedding health advocacy into curricula so that individual optometrists, regardless of their sphere of practice, are able to better influence the health system towards these targeted objectives as part of a country's collective efforts in support of the UN Resolution on Vision. The World Health Organization (WHO)'s Global Strategy on Human Resources for Health 2030 also acknowledges the need for transformative strategies for educating the health workforce, as well as optimising health worker performance, quality and impact to contribute to healthy lives, effective universal healthcare (UHC) and strengthened health systems at all levels. ${ }^{8}$

Little is known about the inclusion of these expanded competencies for eye health workers across the world, and in particular, health advocacy as an outcome competency in the training of optometrists. 
In Africa, available evidence is that there is a significant unmet need for eye care services. ${ }^{9}$ Therefore, to address this need, all stakeholders in eye healthcare must become active advocates for removing barriers to accessing vision care services, as well as the expansion of eye care services to those who need them. Thus, it has become increasingly necessary for health advocacy to be included as an outcome competency in the education and training of optometrists.

Finally, the WHO proposes integrated, people-centred eye care (IPCEC) as an approach to strengthening health systems towards improved delivery of services. ${ }^{9}$ The WHO envisages that IPCEC can help address significant eye care challenges that countries face, because it adopts a strategic healthsystems perspective, including: (1) engaging and empowering people and communities; (2) reorienting the model of care based on a strong primary care foundation; (3) coordinating services within and across sectors; and (4) creating an enabling environment, specifically the inclusion of eye care in national health strategic plans, the integration of relevant eye care relevant data within health information systems, and planning for the eye care workforce according to a country's population needs. ${ }^{10}$ Therefore, for countries to realise their responsibilities in support of the WHO's IPCEC strategy and the UN's Resolution of Vision, the need for strong advocacy efforts from all stakeholders, specifically optometrists who bear the responsibility of reducing uncorrected refractive error as a major cause of avoidable vision impairment, and the largest contributor to the global public eye health burden, is necessary. It also stands to reason that for optometrists to be effective health advocates, they must not only understand health advocacy, but also be trained to effectively advocate for improved health equity and eye health outcomes of populations. This 'fit for purpose' approach will ensure that health systems, policies and programmes are designed and optimised in a manner best suited to addressing the local needs. ${ }^{11}$

\section{References}

1. International Agency for the Prevention of Blindness. UN General Assembly commits countries to eye care for all by 2030 [homepage on the Internet]. 2021. Available from: https://www.iapb.org/news/un-resolution-vision/ [cited 2021 Sep 9].

2. Holden B. The role of optometry in Vision 2020. Community Eye Health. 2002;15(43):33-36.

3. Honavar SG. The burden of uncorrected refractive error. Indian J Ophthalmol. 2019 May;67(5):577-578. https://doi.org/10.4103/ijo.IJO_762_19

4. Frank J, Chen L, Bhutta ZA, et al. Health professionals for a new century: Transforming education to strengthen health systems in an interdependent world. Lancet. 2010;376(9756):1923-1958. https://doi.org/10.1016/S0140-6736(10)61854-5

5. Royal College of Physicians and Surgeons of Canada. CanMEDS: Better standards, better physicians, better care [homepage on the Internet]. 2015. Available from: https://www.royalcollege.ca/rcsite/canmeds/canmeds-framework-e [cited 2021 Sep 9].

6. Buthelezi L, Van Staden D. Integrating eye health into policy: Evidence for health systems strengthening in KwaZulu-Natal. Afr Vision Eye Health. 2020;79(1):10p. https://doi.org/10.4102/aveh.v79i1.549

7. Hubinette M, Dobson S, Scott I, Sherbino J. Health advocacy. Med Teach. 2017;39(2):128-135. https://doi.org/10.1080/0142159X.2017.1245853

8. Van Staden D. The universal eye health imperative for Canada: An inescapable reality of unmet need. Can J Public Health. 2020;111:627-630. https://doi. org/10.17269/s41997-020-00307-4

9. Van Staden D, Munsamy A. Integrated, people-centred eye care: Why South Africa needs to prioritise scaling up refractive services. S Afr Med J. 2021:111(10):924-925. https://doi.org/10.7196/SAMJ.2021.v111i10.15918

10. World Health Organization. World Report on Vision [homepage on the Internet]. 2019. Available from: https://www.who.int/publications/i/item/9789241516570 [cited 2021 Sep 10].

11. Taber S, Akdemir N, Gorman L, Van Zanten M, Frank JR. A 'fit for purpose' framework for medical education accreditation system design. BMC Med Educ. 2020;20:306. https://doi.org/10.1186/s12909-020-02122-4 